\title{
Oculomotor and Abducens Nerve Palsy Complicated by Cavernous Sinus Thrombophlebitis Resulting from Acute Sinusitis
}

\author{
Ju Yong Kang, Jung Jun Kim, Ik Joon Choi, and Myung-Chul Lee ${ }^{(D)}$ \\ Department of Otorhinolaryngology-Head and Neck Surgery, Korea Cancer Center Hospital, \\ Korea Institute of Radiological and Medical Science, Seoul, Korea
}

\author{
급성 부비동염 후 발생한 해면정맥동 혈전염에 합병된 동안과 외전 신경마비 \\ 강주용 · 김정준 · 최익준 · 이명철 \\ 한국원자력의학원 원자력병원 이비인후-두경부외과
}

\author{
Received June 10, 2019 \\ Revised August 16, 2019 \\ Accepted August 27, 2019 \\ Address for correspondence \\ Myung-Chul Lee, MD, PhD \\ Department of Otorhinolaryngology- \\ Head and Neck Surgery, \\ Korea Cancer Center Hospital, \\ Korea Institute of Radiological \\ and Medical Science, \\ 75 Nowon-ro, Nowon-gu, \\ Seoul 01812, Korea \\ Tel $+82-2-970-2173$ \\ Fax $+82-2-970-2450$ \\ E-mail entdok@gmail.com
}

\begin{abstract}
Cavernous sinus thrombophlebitis is a rare complication of paranasal sinusitis. The disease can result in a fatal outcome if not treated with proper antibiotics or surgical intervention. Recently, we experienced a case, in which a 58-year-old female presented with oculomotor and abducens nerve palsy resulting from the cavernous sinus thrombophlebitis complicated by paranasal sinusitis. CT and magnetic resonance imaging with contrast enhancement showed right unilateral pansinusitis, left maxillary, ethmoid and sphenoid sinusitis and bilateral cavernous sinus thrombophlebitis. These conditions were resolved by endoscopic sinus surgery, administration of broad spectrum antibiotics and steroid.
\end{abstract}

Korean J Otorhinolaryngol-Head Neck Surg 2019;62(12):731-4

Key Words Abducens nerve $\cdot$ Cavernous sinus $\cdot$ Oculomotor nerve $\cdot$ Sinusitis

Thrombophlebitis.

\section{서 론}

해면정맥동 혈전염의 원인은 크게 감염성과 비감염성으로 나뉜다. 비감염성 원인은 외상, 두개 내 또는 부비동 수술, 자 가면역 질환, 응고항진 질환, 뇌동맥류 등으로 다양하다.1) 감 염성인 경우는 주로 안면부나 부비동, 치아에서 전파되는 염 증에 의하여 발생된다. 특히 급성 부비동염(사골동과 접형동) 이 주요한 원인으로 알려져 있고, ${ }^{2)}$ 이로 인한 두개 내 합병증 에 의해서 발생한 해면정맥동 혈전염은 드물지만, 치명적인 질환이어서 빠른 진단과 치료에도 불구하고 심각한 후유증 을 남길 수 있다. ${ }^{3)}$ 수반되는 임상증상으로는 발열, 두통, 복시,

This is an Open Access article distributed under the terms of the Creative Commons Attribution Non-Commercial License (https://creativecommons.org/licenses/by-nc/4.0) which permits unrestricted non-commercial use, distribution, and reproduction in any medium, provided the original work is properly cited.
안와 주위 부종, 결막 부종, 안구운동 장애, 시력 소실 등이 있다.")

저자들은 급성 부비동염에 병발된 해면정맥동 혈전염에 의해 발생한 동안 및 외전 신경마비를 보인 환자에서 빠른 진단, 적극적인 수술과 약물 치료를 통한 완치를 경험하여 문헌 고찰과 함께 보고하고자 한다.

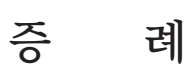

58세 여자 환자가 내원 2일 전부터 시작된 두통과 가벼운 비회전성 어지럼증으로 본원 신경과에 내원하였다. 환자는 기저 질환이 없이 건강하던 자로 두통은 간헐적으로 머리 전 반적인 부위에서 발생한다고 하였고, 신경학적 검사상 이상 소견은 보이지 않았다. 말초성 현훈 감별 위해 두부충동 검 
사, 두위충동 검사, 두위안진, 냉온교대 온도안진 검사(bithermal caloric test) 등을 시행하였으나 특이 소견은 관찰되지 않았다. 이에 추가 정밀 검사 및 보존적 치료를 위해 신경과로 입원하였다. 일반 혈액 검사에서 백혈구는 $10.07 \times 10^{3} / \mathrm{uL}$ 에 중

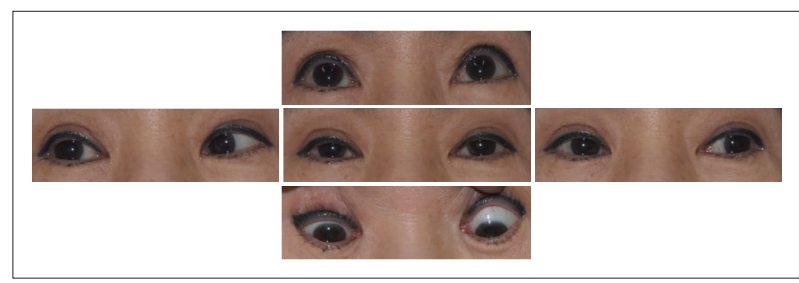

Fig. 1. Preoperative eyeball position. Extraocular movement motion test shows eyelid ptosis and limitation of right eyeball movement including abduction, adduction, elevation, and depression.

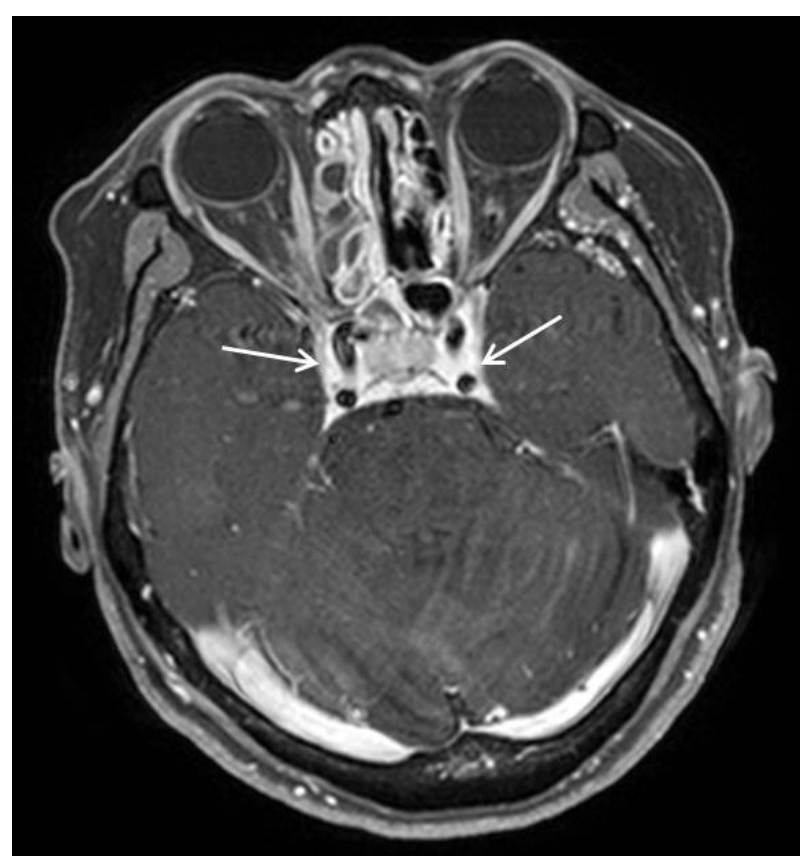

Fig. 2. Preoperative axial scan of posterior fossa MRI image at the level of cavernous sinus. T1 weighted MRI with contrast enhancement shows mucosal edema of right ethmoid and sphenoid sinuses with dural thickening and bulging of both cavernous sinuses without definite evidence of thrombus formation representing right ethmoid and sphenoid sinusitis and bilateral cavernous sinus thrombophlebitis (arrows).
성구 $81 \%$, 적혈구 침강속도는 $86 \mathrm{~mm} / \mathrm{hour}$ 로 증가되었으나 그 외 검사상 다른 이상 소견은 보이지 않았다. 뇌 확산 자기 공명영상(brain MR diffusion)을 촬영하였고, 허혈성 병변 및 뇌실질의 병변은 확인되지 않았으나, 우측 사골동과 접형동 부비동염 의심 소견이 확인되었다. 입원 2일째 환자가 갑작스 러운 복시와 우측 안검하수를 호소하여 시행한 안과 검진상 시력, 안압 등은 정상이었고, 안구 운동 시 우안의 내전, 외전, 상전, 하전 제한과 안검하수가 관찰되었다(Fig. 1). 우측 사골 동과 접형동 부비동염 및 우측 동안 및 외전 신경 마비 의심 하에 부비동 전산화단층촬영(paranasal sinus CT, PNS CT) 및 후두와 자기공명영상(posterior fossa MRI)을 시행하였 다. MRI에서 팽윤된 양측 해면정맥동과 주변 경막의 비후 소 견이 관찰되었으며, 상기 소견은 우측이 더 심하였고 혈전 형 성은 보이지 않았다(Fig. 2). PNS CT상 우측 전두동, 상악동, 사골동과 접형동의 연부조직음영이 있었으며, 좌측 상악동, 사골동과 접형동에도 일부 음영증가 소견이 보였고, 골결손 은 보이지 않았다(Fig. 3). 환자는 코막힘, 후각 감퇴, 콧물, 재 채기 등의 비증상은 호소하지 않았으나, 비강 검사상 좌측 비 중격 만곡증 및 양측 비용 소견이 관찰되었다. 임상학적 양상과 영상 소견을 종합한 결과 급성 부비동염에 병발된 해면정맥 동혈전염으로 인한 우측 동안 및 외전 신경마비로 의심되어 부비동 내시경 수술과 항생제와 스테로이드 정맥주사( $\mathrm{ampi}^{-}$ cillin/sulbactam $1.5 \mathrm{~g}$ tid, cefotaxime $1 \mathrm{~g}$ tid, metronidazole $500 \mathrm{mg}$ tid, dexamethasone $5 \mathrm{mg}$ bid)를 진행할 것을 계획하였다. 입원 3일째, 전과 후 비중격 교정술과 양측 부비 동 내시경술을 시행하였다. 전신마취하에 비중격 교정술 후 우측 전두동, 상악동, 사골동의 비용과 병변 점막을 제거하면 서 자연공을 충분히 넓혔으며, 접형동 개구술을 통해 배농을 시행하였다(Fig. 4). 좌측 사골동, 상악동, 접형동도 비용과 병 변 점막 제거 및 개방술을 진행하였다. 술 후 1 일째, 두통, 어 지럼증과 안검하수는 호전되었으나, 복시는 지속되는 양상이 었다. 술 후 5일째에 안검하수 증상은 개선되었고, 우측 주시 시 여전히 복시를 호소하였다. 술 후 7일째 퇴원하고 경구 항
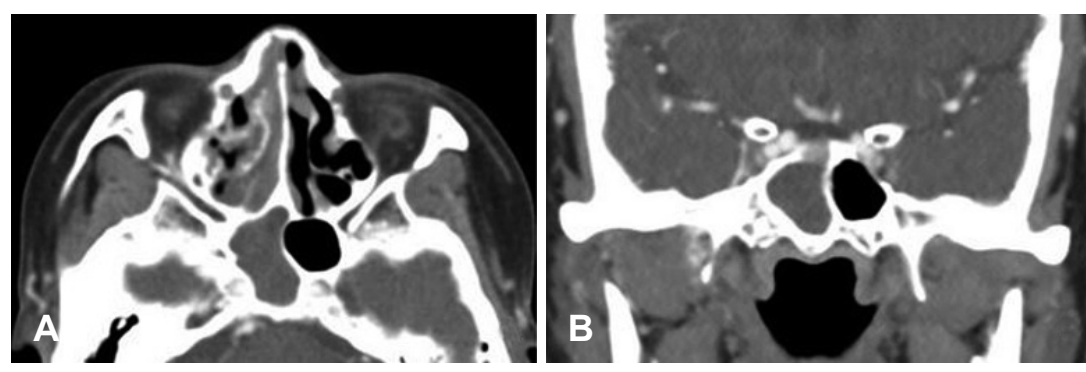

Fig. 3. Preoperative axial $(A)$ and coronal $(B$ and $C)$ contrast-enhanced paranasal sinus $C T$ images. These images show nasal septal deviation to left, opacification of the right ethmoid and sphenoid sinuses and mucosal edema of the left ethmoid sinus representing both ethmoid and right sphenoid sinusitis. 
생제, 경구 스테로이드, 비강 스테로이드제(amoxicillin/clavulanate potassium $1 \mathrm{~g}$ bid, prednisolone $10 \mathrm{mg}$ bid, fluticasone $5 \mathrm{mg} \mathrm{qd}$ )를 3주간 사용하였다. 추적 관찰하기 위해 촬 영한 PNS CT상 양측 상악동, 사골동과 접형동의 부비동염 양상은 대부분 호전되었다(Fig. 5). 술 후 1개월째 안과 진료 를 통해 복시가 개선된 것으로 확인되었고, 수술 2개월경 시 행한 안과 검진상에서 외안근 기능이 모두 정상화된 것을 확 인할 수 있었다(Fig. 6).

\section{고 찰}

감염성 해면정맥동 혈전염은 안면부, 부비동, 구강 내 세균 성 혹은 진균의 감염에 의해 직접 전파되거나 정맥을 통하여 침범될 수 있는 치명적인 질환으로, 조절되지 않는 당뇨나 면 역억제제를 사용하는 환자에서 발생할 수 있다. 해면정맥동 의 해부를 이해해야 해면정맥동 혈전염의 병태생리 및 질병 경과를 파악할 수 있다. 해면정맥동은 머리에 있는 경막정맥 동의 하나로 내측으로 지나가는 구조물로는 외전 신경, 해면

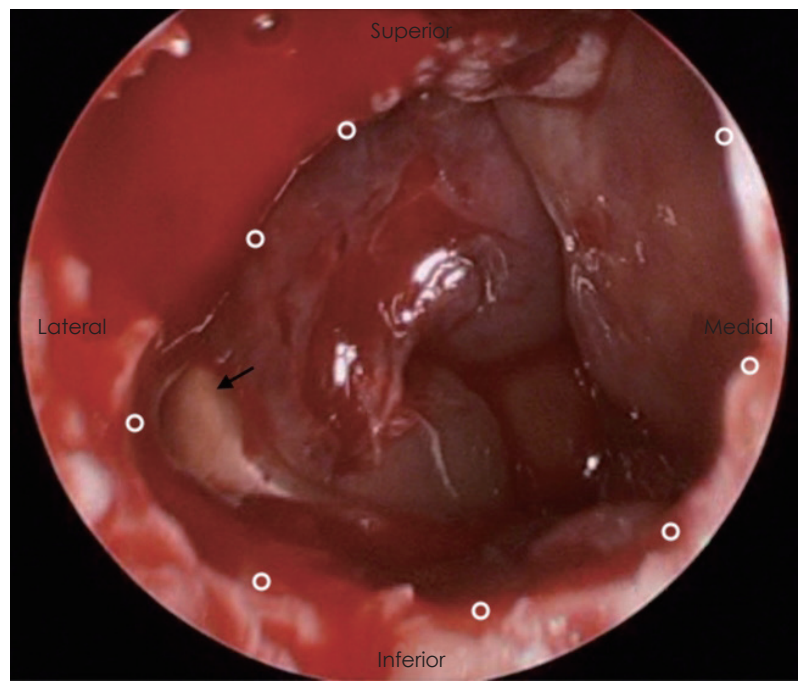

Fig. 4. Intraoperative endoscopic finding of the right sphenoid sinus shows severe mucosal edema and pus (arrow). Circles attached in the photo depict the border of widened sphenoid ostium.
정맥동 내 내경동맥 부위와 교감신경총이 있고, 외측으로는 동안 및 활차신경, 삼차신경의 안분지와 상악분지가 지나간 다. ${ }^{5)}$ 해면정맥동은 판막이 없어 압력 차에 의하여 혈류가 이 동하게 되는데, 감염성 혈전정맥염의 경우에는 수입성 및 수 출성 정맥을 통해 역행성으로 염증이 직접 전파되거나, 정맥 색전이 해면정맥동에 도달되어 시작된다.)

해면정맥동 혈전염 환자의 약 $50 \%$ 에서 두통을 호소하며, 부비동염에 의한 경우 더 흔하게 나타난다. 그 외 증상으로 상안정맥 폐쇄로 인한 안구돌출증, 안검부종, 결막 부종이

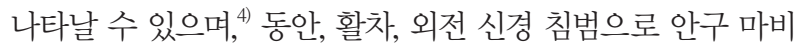
가 발생하여 복시나 눈 주위 통증, 안검하수가 나타날 수 있 다.7) 질환이 점차 진행되어 뇌막염이 발생되면, 뇌막자극 증상 이 관찰될 수 있다. ${ }^{5)}$ 해면정맥동 내 구조물의 해부학적 특성 중, 외전 신경은 길이가 길고 접형동과 가까운 내측에 위치하 고 있어서, 접형동 병변에 의한 정맥혈전염의 경우, 외전 신경 마비로 인한 복시가 다른 신경학적 증상에 비해 먼저 나타날 수 있다. ${ }^{6,8)}$ 반대로 수술이나 항생제 치료를 통해서 원인 부비 동 질환이 치료가 되면 부비동에서 비교적 거리가 먼 쪽의 동 안신경의 마비에 의한 안검하수 증상이 먼저 개선되고, 이후 가까운 쪽의 외전신경의 마비에 의한 복시가 개선될 것으로 생각되며, 본 증례에서도 비슷한 경과를 보였다.

해면정맥동 혈전염의 진단을 위해서는 전산화단층촬영이 가장 중요하며 우선적으로 시행되어야 한다. 이를 통해 접형 동의 함기화 정도 및 골미란 여부와 접형동 병변과의 관계성 을 확인해 볼 수 있으며, 골미란 소견이 있거나, 시력 저하, 복 시, 안검하수 등 뇌신경마비 소견이 보이는 경우 뇌 자기공명

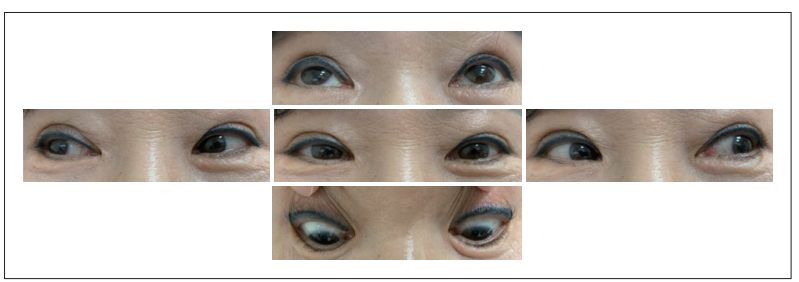

Fig. 6. Eyeball position in postoperative 2 months extraocular movement motion test represents normal extraocular muscle function in both eyes.

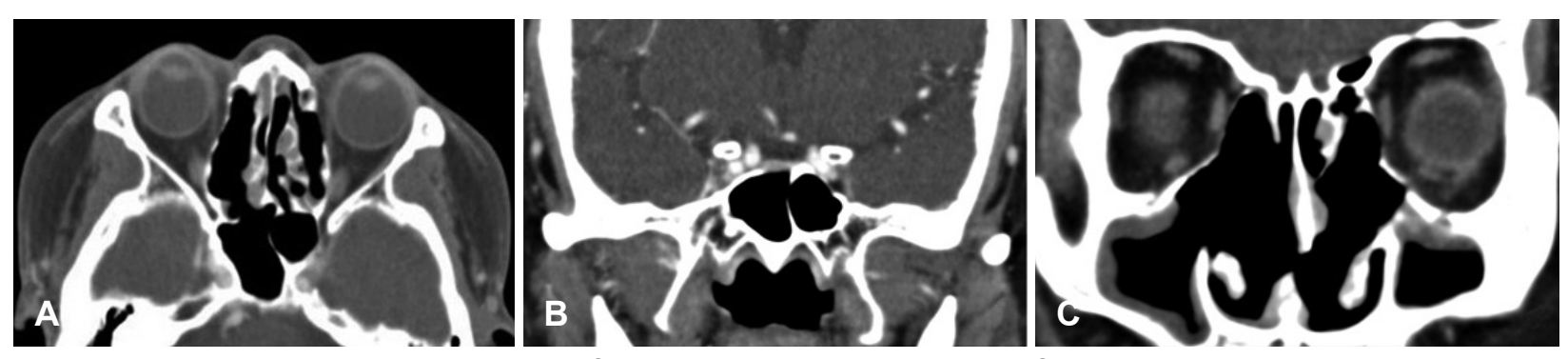

Fig. 5. Postoperative axial $(A)$ and coronal $(B$ and $C)$ contrast-enhanced paranasal sinus $C T$ images. These images show improvement of the deviated nasal septum, both ethmoid and sphenoid sinusitis. 
영상을 추가로 시행해야 한다. ${ }^{8,9)}$ 해면정맥동 혈전염의 자기공 명영상 소견으로는 해면정맥동의 비대칭적 팽창과 혈전 형성 을 시사하는 해면정맥동 내 불규칙한 다발성 충만 결손(filling defect), 해면정맥동 내 내경동맥(intracavernous internal carotid artery)의 현저한 내경 감소 및 해면정맥동 주위 경막 의 조영증강 등이 있고, 상안정맥 확장이나 안구 돌출 양상도 보일 수도 있다. ${ }^{57,10)}$ 본 증례에서는 뇌 자기공명영상에서 양측 해면정맥동의 팽창 및 주변 경막의 조영 증강 소견을 보여 해 면정맥동 병변을 의심해볼 수 있었으며, 충만 결손은 확인되 지 않아 혈전은 뚜렷하게 생성되지 않았음을 확인하였다. 영 상 소견에서는 양측 해면정맥동 혈전염이 확인되었지만, 환자 는 우측에서만 안증상을 보였다. 해면정맥동 혈전염은 양측 으로 교통되어 있어서, 원인 질환이 일측이라도 양측으로 금 방 전파될 수 있다.111) 본 증례에서는 우측 사골동염과 접형동 염이 상대적으로 심하였기 때문에 안증상이 우측에서 먼저 확인되었고, 빠른 치료가 없었으면 좌측 안증상도 발생했을 가능성이 있다고 생각된다.

감염성 해면정맥동 혈전염의 치료는 즉각적인 광범위 항생 제, 스테로이드, 항응고 요법으로 알려져 있고, 항생제 투여 후 24 48시간 이내에 증상 호전이 없거나, 신경학적 합병증 이 생겼을 경우, 진균성 감염, 악성종양이나 기타 종물이 의 심되는 경우에 수술적 방법을 통해 감염 병소를 적절하게 제 거하는 것이 필요하다. ${ }^{8}$ 항응고제와 스테로이드의 투여는 그 효과 면에서 이견이 많다. ${ }^{10-13)}$ 본 증례에서는 신경학적 합병증 소견 보여 수술을 바로 결정하였고, 뇌신경 부종을 완화시키 기 위해 스테로이드도 투여하였다. ${ }^{12,13)}$ 항응고 요법은 혈전 개 통을 통해 항생제 작용을 효과적이게 한다는 보고가 있으 나, ${ }^{7,10)}$ 효과면에서 이견이 있어 뇌 자기공명영상에서 명백한 혈전 소견이 없는 것을 확인 후 항응고 요법은 시행하지 않았 다. 해면정맥동 혈전염의 예후는 적절한 항생제의 적극적인 사용으로 사망률이 항생제 사용 이전 시대의 80 100\%에서 최근은 $20 \%$ 이하로 보고되고 있다. 이환율도 조기 진단과 치 료로 $70 \%$ 에서 $22 \%$ 로 좋아졌지만 영구적인 뇌신경마비 증상 을 보일 수 있어 주의를 요한다. ${ }^{14,15)}$

본 증례에서 저자들은 두통과 가벼운 어지럼을 주소로 내 원하여 시행한 MRI에서 우연히 발견된 급성 부비동염과 해 면정맥동 혈전염에 병발된 동안 및 외전 신경마비로 인한 복 시와 안검하수를 치료하였다. 환자는 콧물, 코막힘 같은 부비 동염의 특징적인 증상을 호소하지 않아서 초기에 환자의 상 태를 평가하는 데 어려움이 있었으나, 영상학적 소견을 바탕
으로 빠른 임상적 평가를 진행하여 해면정맥동 혈전염을 파 악하였고, 조기에 부비동 내시경 수술과 항생제, 스테로이드 등의 적극적인 치료를 시작하여 추가적인 안구 및 두개 내 합 병증 없이 증상이 호전되었다. 이는 치명적인 합병증을 남길 수 있는 해면정맥동 혈전염에서 조기 진단과 빠르고 적극적인 치료의 중요성을 보여주는 좋은 예라 사료되어 문헌 고찰과 함께 보고하는 바이다.

\section{Acknowledgments}

None.

\section{ORCID}

Myung-Chul Lee https://orcid.org/0000-0002-2574-4976

\section{REFERENCES}

1) Lai PF, Cusimano MD. The spectrum of cavernous sinus and orbital venous thrombosis: A case and a review. Skull Base Surg 1996; 6(1):53-9.

2) Southwick FS, Richardson EP Jr, Swartz MN. Septic thrombosis of the dural venous sinuses. Medicine (Baltimore) 1986;65(2):82-106.

3) Sofferman RA. Cavernous sinus thrombophlebitis secondary to sphenoid sinusitis. Laryngoscope 1983;93(6):797-800.

4) Ebright JR, Pace MT, Niazi AF. Septic thrombosis of the cavernous sinuses. Arch Intern Med 2001;161(22):2671-6.

5) Park SN, Yeo SW, Rhyoo JY, Lee HY. A Case of cavernous sinus thrombophlebitis and abducence nerve palsy secondary to petrositis. Korean J Otolaryngol-Head Neck Surg 2002;45(1):82-5.

6) Tveterås K, Kristensen S, Dommerby H. Septic cavernous and lateral sinus thrombosis: Modern diagnostic and therapeutic principles. J Laryngol Otol 1988;102(10):877-82.

7) Prabhu S, Jain SK, Dal Singh V. Cavernous sinus thrombophlebitis (sans thrombosis) secondary to odontogenic fascial space infection: An uncommon complication with unusual presentation. J Maxillofac Oral Surg 2015;14(Suppl 1):168-72.

8) Ruoppi P, Seppä J, Pukkila M, Nuutinen J. Isolated sphenoid sinus diseases: Report of 39 cases. Arch Otolaryngol Head Neck Surg 2000;126(6):777-81.

9) Park JO, Cho JK, So YK, Hong SD. Acute rhinosinusitis in prominently pneumatized sphenoid sinus presenting with unilateral abducens nerve palsy. Korean J Otolaryngol-Head Neck Surg 2015;58(4):271-4.

10) Bhatia K, Jones NS. Septic cavernous sinus thrombosis secondary to sinusitis: Are anticoagulants indicated? A review of the literature. J Laryngol Otol 2002;116(9):667-76.

11) Dolapsakis C, Kranidioti E, Katsila S, Samarkos M. Cavernous sinus thrombosis due to ipsilateral sphenoid sinusitis. BMJ Case Rep 2019;12(1):e227302.

12) Desa V, Green R. Cavernous sinus thrombosis: Current therapy. J Oral Maxillofac Surg 2012;70(9):2085-91.

13) Solomon DO, Moses L, Volk M. Steroid therapy in cavernous sinus thrombosis. Am J Ophthalmol 1962;54(6):1122-4.

14) Yarington CT Jr. Cavernous sinus thrombosis revisited. Proc R Soc Med 1977;70(7):456-9.

15) Lee LA, Huang CC, Lee TJ. Prolonged visual disturbance secondary to isolated sphenoid sinus disease. Laryngoscope 2004;114(6):986-90. 